\title{
Immunohistochemical expression of estrogens and progesterone receptors in carcinoma ex pleomorphic adenoma-undifferentiated and adenocarcinoma types
}

\author{
Bassel Tarakji ${ }^{1}$, Mohammad Z Nassani ${ }^{2}$, Philip Sloan ${ }^{3}$
}

\author{
${ }^{1}$ Head of Department of oral pathology, Faculty of Dentistry, Aleppo University, Aleppo, Syria \\ ${ }^{2}$ Head of Department of Prothodontics, Faculty of Dentistry, Aleppo University, Aleppo, Syria \\ ${ }^{3}$ School of Dental Sciences, Newcastle University, Newcastle, Untied Kingdom
}

Correspondence:

Head of Department of oral pathology

Faculty of dentistry

Aleppo University

Aleppo, Syria

denpol@yahoo.co.uk

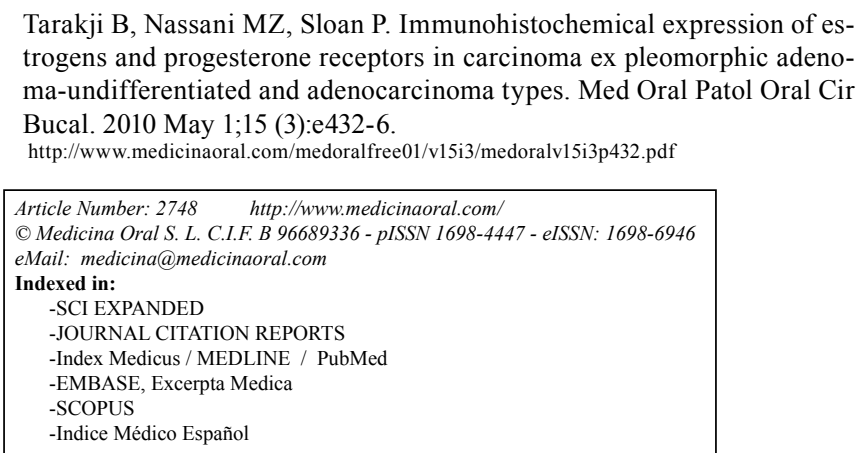

\begin{abstract}
Cancer of the salivary gland is one of the common cancers in the head and the neck regions. This type of cancer develops in the minor and the major salivary glands, and it sometimes metastasizes to other organs, particularly the lung. Morphologic mimicry and similarity in the expression of steroid hormone receptors between salivary gland tumors and breast tumors are well-known phenomena and are occasionally debated in the field of surgical pathology. The expression of sex hormone receptors in some tumors suggests a role for these receptors in tumor pathogenesis and therapy. Previous studies of the expression of estrogens and progesterone receptors in salivary gland tumors have reported conflicting results.

Objective: Our study aimed to characterize alteration in the immunohistochemical expression of estrogens receptor and progesterone receptor in the tumor cells of carcinoma arising in pleomorphic adenoma. Study design: 27 cases of carcinoma arising in pleomorphic adenoma (undifferentiated and adenocarcinoma types) were examined.

Results: The results showed that 27 (100\%) of 27 cases had negative nuclear staining for either estrogens or progesterone receptors.

Conclusion: Our data suggest that carcinomas arising in pleomorphic adenoma were not dependent on endocrine function.
\end{abstract}

Key words: Estrogens receptor, progesterone receptor, pleomorphic salivary adenoma, salivary carcinoma. 


\section{Introduction}

Salivary gland carcinomas account for $0.4 \%$ of all cancers and $5 \%$ of all head and neck malignancies (1). The use of molecular biology technique has aided in studying such these tumors (2). Although some salivary gland tumors are benign, but they have shown metastasis (3), therefore, those tumors are very dangerous. Salivary gland carcinomas are histologically similar to certain types of breast carcinoma (4). The discovery of hormonal receptors facilitated the identification of breast cancer patients who can get the benefit from hormone therapy (5). Immunocytochemical techniques have shown nuclear distribution of estrogens and progesterone receptors in carcinoma of breast cells and benign lobular or ductal epithelial cells, with no specific staining seen in the surrounding connective tissue. Immunocytochemistry of estrogens receptor has been shown to predict response of breast cancer to endocrine therapy (6-7). Previous studies (8-12) reported that some tumors other than breast cancer have hormone receptors e.g melanoma, carcinoid tumors, pancreatic, and renal cancers. It is unknown whether salivary gland cancers are hormone dependent or independent. The purpose of this study was to determine, with the use of immunohistochemistry, if Estrogens receptor and progesterone receptor can be identified in formalin- fixed paraffin embedded tumor cells of carcinoma arising in pleomorphic adenoma.

\section{Materials and Methods}

The proposed criteria for defining carcinoma ex-pleomorphic adenoma by Nagao et al. (13) were used to select and reclassify our cases of carcinoma ex-pleomorphic adenoma.

The use of strict pathological criteria may underestimate the frequency of carcinoma ex pleomorphic adenoma because the malignant cells in some cases may obliterate the original pleomorphic adenoma.

Inclusion criteria for carcinoma ex-pleomorphic adenoma

- Major gland primary lesion (parotid or submandibular)

- Co-existent benign and malignant elements benign element can be:

- Pleomorphic adenoma within the tumor mass

- Biopsy proven history of previous PSA (pleomorphic salivary adenoma) indicated that it was in the same location as the subsequent carcinoma. Malignant elements can be:

- Undifferentiated carcinoma

- Adenocarcinoma

- Multiple patterns of differentiation including undifferentiated or adenocarcinoma patterns
Exclusion criteria for carcinoma ex-pleomorphic adenoma includes any other type of tumor.

Twenty seven cases of carcinoma arising in pleomorphic adenoma were included in this study. Immunostaining techniques were applied to localize the estrogens and progesterone receptors in the tissues.

Nuclear staining of estrogen and progesterone receptors was considered only as a positive result indicating presence of receptor proteins. Two independent examiners scored the sections for the presence of estrogens and progesterone receptors. Following examination the entire section, five random areas were chosen from each slide. The scoring criteria was considered two categories: positive or negative nuclear staining. Estrogens receptor or progesterone receptor positive nuclei was assessed by two independent observers and scored as: as negative is $<75 \%$ staining and positive as greater than $75 \%$ of cells.

The local NHS Research Ethics Committee provided a favorable ethical opinion (Ref: 02/104).

Tissue blocks of breast carcinoma with normal surrounding tissue, of known positive (five specimens) and negative (five specimens) estrogens and progesterone receptors status were used as positive controls.

\section{Immunhistochemistry}

Paraffin-embedded, 4- $\mu$ m-thick tissue sections from all 27 specimens were cut. The sections were deparaffinized in xylene and rehydrated through graded alcohols. Sections were processed used streptavidin-biotinperoxidase method. Briefly, the endogenous peroxidase was blocked by $3 \%$ hydrogen peroxidase for $5 \mathrm{~min}$ followed by TBS wash. Non specific immunoreactivity was blocked by incubation with normal goat serum for 20 minutes. Dako mouse anti-human Estrogens receptor OR 1D5 was diluted to 1: $25(40 \mu \mathrm{L} / \mathrm{ml})$ in tris buffer saline (TSA) containing $0.1 \%$ bovine serum albumin for 10 minutes at the room temperature. Dako mouse anti-human progesterone receptor PR 636 was diluted to $10 \mu / \mathrm{ml}$ in tris buffer saline (TSA) containing $0.1 \%$ bovine serum albumin for 10 minutes at the room temperature. All sections were washed by TBS for 5 minutes. Sections were incubated with the biotinylated secondary antibody reagent for 10 minutes followed by (TBS) wash for 5 minutes. Slides were incubated with streptavidin and horseradish peroxidase for 10 minutes followed by (TBS) tris buffer saline wash for 5 minutes. Incubate with a prepared chromogenic substrate solution (Diaminobenizidine) for 15 minutes. Sections were counterstained with $0.25 \%$ methyl green in distilled water for 5 minutes. Sections were dehydrated and mounted in Depax. Breast cancer was used as positive control. Negative control was used only with substitution the primary antibody with TBS.

Statistical analysis

The data were described using frequency distribution. 


\section{Results}

The results showed that 27 (100\%) of 27 cases had negative nuclear staining for either estrogens or progesterone receptors. 17 cases out of 27 (63\%) showed estrogens positive cytoplasmic staining but 10 cases out of 27 (37\%) showed estrogens negative cytoplasam staining. 5 cases out of $27(18.5 \%)$ showed progesterone positive cytoplasam staining but 22 cases out of 27 (81.5\%) showed progesterone negative cytoplasam staining. The positive nuclear staining (positive control) from breast cancer of the estrogens and progesterone receptors, and negative nuclear staining for either estrogens or progesterone receptors in carcinoma arising in pleomorphic adenoma are shown in (Fig. 1-4). The Clinical hit-

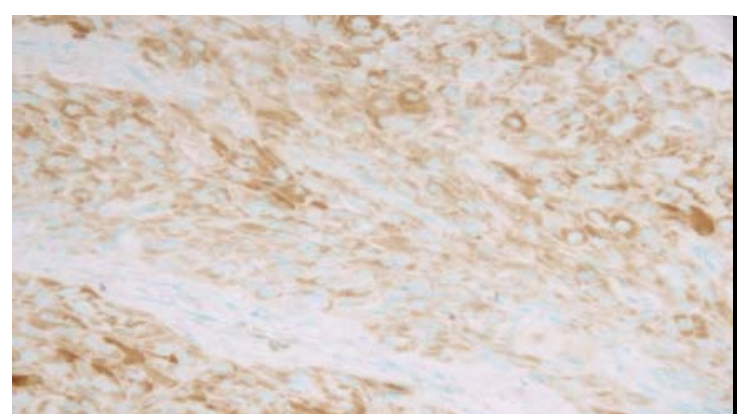

Fig. 1. Showing negative nuclear and weak positive cytoplasmic staining of Carcinoma ex pleomorphic adenoma for progesterone receptor. Original magnification $\mathrm{x} 40$.

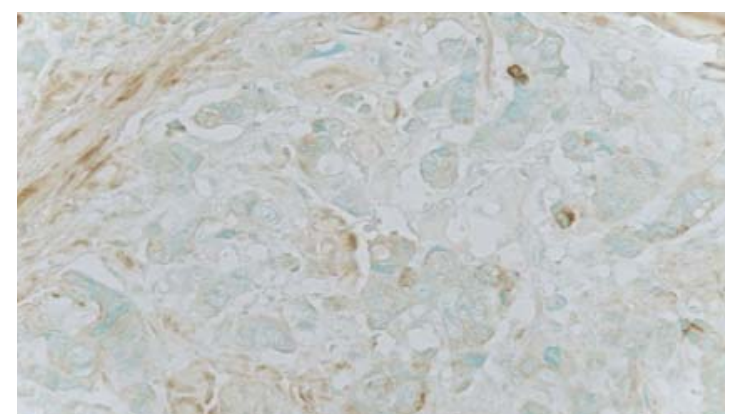

Fig.2. ShowingnegativenuclearstainingofCarcinomaexpleomorphic adenoma for oestrogen receptor. Original magnification $\times 40$.

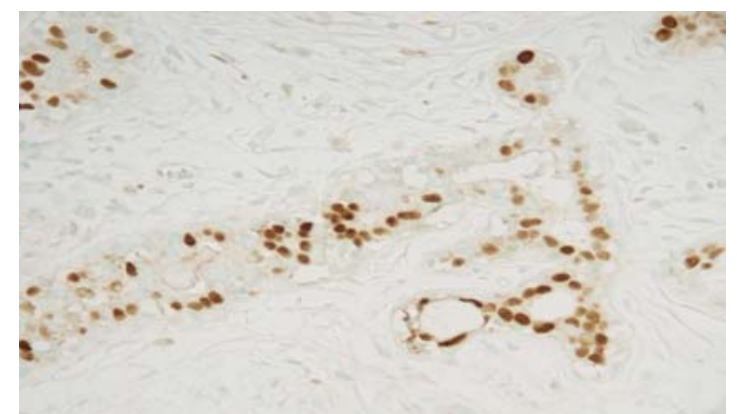

Fig. 3. Showing positive nuclear staining of progesterone receptor in normal breast tissue surrounding a carcinoma. Original magnification $\mathrm{x} 40$.

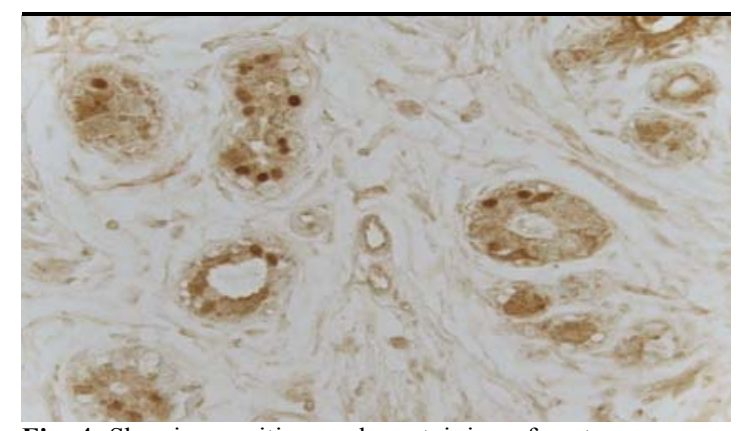

Fig. 4. Showing positive nuclear staining of oestrogen receptor in normal breast tissue surrounding a carcinoma. Original magnification $\times 40$.

sopathological and immunohistochemical characterization of estrogens and progesterone receptors in carcinomas ex-pleomorphic adenomas are shown in (Table 1).

\section{Discussion}

The assessment of the positive or negative nuclear staining cells is controversial. Many authors (14-16) used different criteria e.g $(0=$ negative staining, $1=$ low, $2=$ moderate, $3=$ strong or $0-3=$ negative and $4=$ positive or $0-2=$ negative and $3-4=$ positive or negative and positive staining) so the results cannot be compared, therefore, we have used a strict criteria to assess the negative and positive staining to avoid any confusion in the interpretation of the results. The rational of $75 \%$ break point may provide a more complete assessment of protein expression and a clearer understanding of the roles played by potential tumour markers in predicting outcome. Estrogens and progesterone nuclear staining were not detected in our cases of carcinoma arising in pleomorphic adenoma. This is the first study to assess the presence of progesterone and estrogens receptors in carcinoma arising in pleomorphic adenoma. Dimery et al. (8) detected 15 of 19 (79\%) cases of normal salivary gland tissue and 3 out of four adenoid cystic carcinomas to be estrogens receptor positive, but their study used a less specific filtration assay of estradiol titration on pulverized fresh frozen tissue in which stromal components such as fibrous tissue and blood vessels were included. These stromal tissues can bind tritiated estradiol, thus providing false positive results. In the present study immunohistochemical staining was used which allows direct visualization of positive cells. The results are consistent with those of Shick et al. (17) who found no estrogens receptor in their cases of adenoid cystic carcinoma. Dori et al. (18) found 2 cases with progesterone positive staining out of 27 adenoid cystic carcinoma but estrogens receptor was negatively expressed in all cases. Miller et al. (19) found the estrogens receptor was absent in their cases of polymorphous low-grade adenocarcinoma 


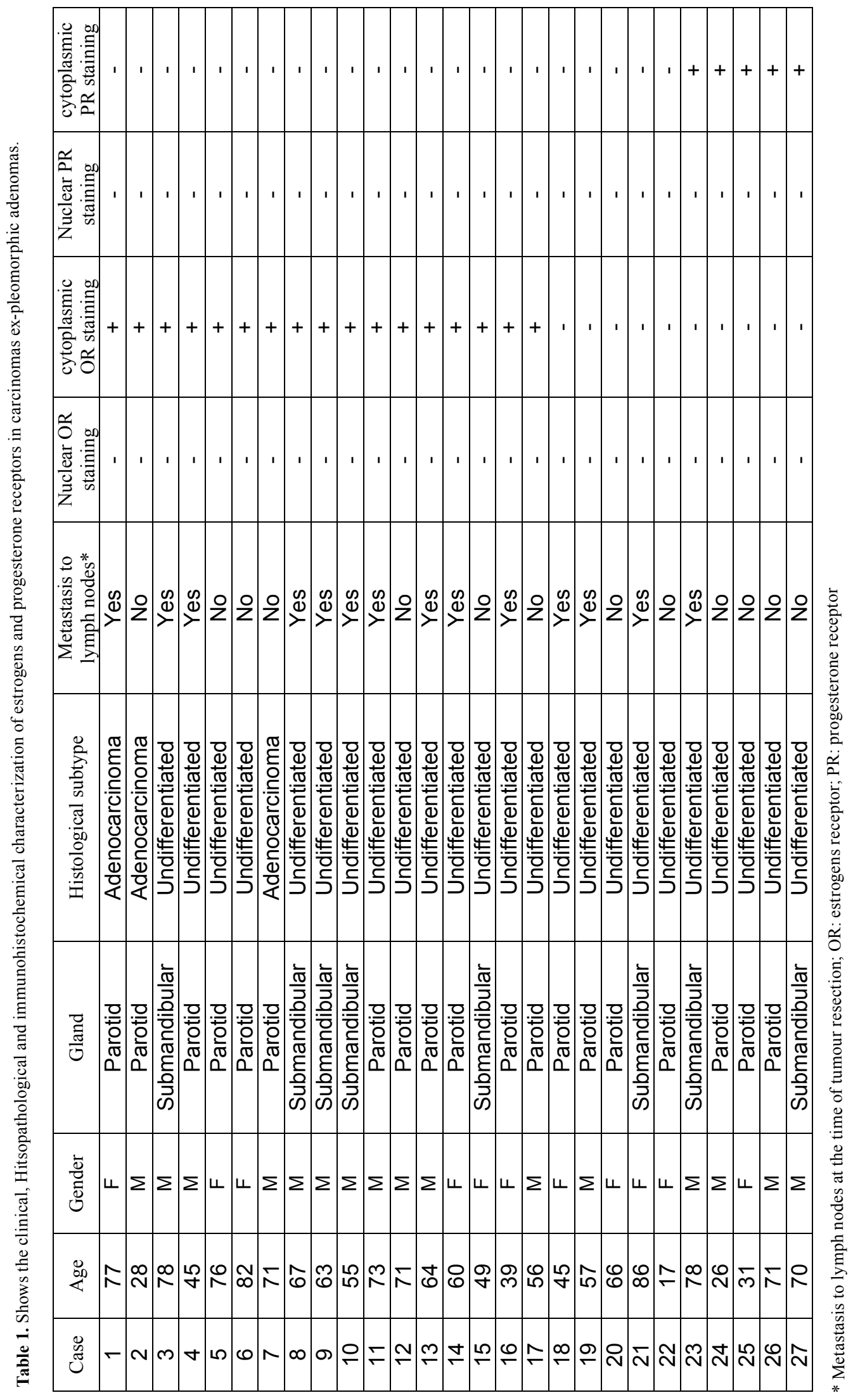


and adenoid cystic carcinoma of salivary gland origin. Nasser et al. (20) have indicated that estrogens and progesterone receptors were expressed in only a few cases of salivary gland tumors. The difference in the results with the present study might be due to various factors: gender, age, specific tumour histology, immunohistochemical technique and the pathological interpretation of the staining due to a lack of strict evaluation criteria.

\section{Conclusion}

The results suggested that carcinomas arising in pleomorphic adenoma were not dependent on endocrine function. The study included 27 cases of carcinoma arising in pleomorphic adenoma, which was a large sample compared with many other studies. It is recommended that further work involves a large series of carcinoma arising in pleomorphic adenoma to determine if estrogens and progesterone receptors using sensitive and specific biochemical methods can be detected in those tumors. Other receptors, such as EGF for which therapeutic drugs are available could also be examined.

\section{References}

1. Olejniczak I, Kozłowski Z, Dabrowska K, Lukomski M. [Tumors of the parotid gland--management and results of surgical treatment]. Otolaryngol Pol. 2008;62:446-50.

2. Do Prado RF, Consolaro A, Taveira LA. Expression of betacatenin in carcinoma in pleomorphic adenoma, pleomorphic adenoma and normal salivary gland: an immunohistochemical study. Med Oral Patol Oral Cir Bucal. 2006;11:E247-51.

3. Rodríguez-Fernández J, Mateos-Micas M, Martínez-Tello FJ, Berjón J, Montalvo JJ, Forteza-González G, et al. Metastatic benign pleomorphic adenoma. Report of a case and review of the literature. Med Oral Patol Oral Cir Bucal. 2008;13:E193-6.

4. Bretschneider N, Brand H, Miller N, Lowery AJ, Kerin MJ, Gannon $\mathrm{F}$, et al. Estrogen induces repression of the breast cancer and salivary gland expression gene in an estrogen receptor alpha-dependent manner. Cancer Res. 2008;68:106-14.

5. Ma CX, Sanchez CG, Ellis MJ. Predicting endocrine therapy responsiveness in breast cancer. Oncology (Williston Park). 2009;23:133-42.

6. Pertschuk LP, Eisenberg KB, Carter AC, Feldman JG. Immunohistologic localization of estrogen receptors in breast cancer with monoclonal antibodies. Correlation with biochemistry and clinical endocrine response. Cancer. 1985;55:1513-8.

7. Singh Y, Sayami P, Sayami G, Nakagawa H, Koreeda T, Hatano $\mathrm{T}$, et al. Nepalese breast cancer in relation to reproductive factors: comparison between Nepalese and Japanese cases. Anticancer Res. 2002;22:319-23.

8. Dimery IW, Jones LA, Verjan RP, Raymond AK, Goepfert H, Hong WK. Estrogen receptors in normal salivary gland and salivary gland carcinoma. Arch Otolaryngol Head Neck Surg. 1987;113:1082-5.

9. Driscoll MS, Grant-Kels JM. Estrogen receptor expression in cutaneous melanoma. Arch Dermatol. 2009;145:73-5.

10. Ripoll C, Ropero AB, Alonso-Magdalena P, Quesada I, Fuentes E, Nadal A. Rapid regulation of pancreatic alpha- and beta- cell signalling systems by estrogens. Infect Disord Drug Targets. 2008;8:61-4. 11. Birsak CA, Janssen PJ, Van Vroonhoven CC, Peterse JL, Van der Kwast TH. Sex steroid receptor expression in 'carcinoid' tumours of the breast. Breast Cancer Res Treat. 1996;40:243-9.

12. Mai KT, Teo I, Belanger EC, Robertson SJ, Marginean EC, Islam S. Progesterone receptor reactivity in renal oncocytoma and chromophobe renal cell carcinoma. Histopathology. 2008;52:277-82.
13. Nagao K, Matsuzaki O, Saiga H, Sugano I, Shigematsu H, Kaneko T, et al. Histopathologic studies on carcinoma in pleomorphic adenoma of the parotid gland. Cancer. 1981;48:113-21.

14. Azuma M, Kasai Y, Tamatani T, Sato M. Involvement of p53 mutation in the development of human salivary gland pleomorphic adenomas. Cancer Lett. 1992;65:61-71.

15. Yamamoto Y, Kishimoto Y, Virmani AK, Smith A, Vuitch F, Albores-Saavedra J, et al. Mutations associated with carcinomas arising from pleomorphic adenomas of the salivary glands. Hum Pathol. 1996;27:782-6.

16. Yamamoto Y, Kishimoto Y, Wistuba II, Virmani AK, Vuitch F, Gazdar AF, et al. DNA analysis at p53 locus in carcinomas arising from pleomorphic adenomas of salivary glands: comparison of molecular study and p53 immunostaining. Pathol Int. 1998;48:265-72.

17. Shick PC, Riordan GP, Foss RD. Estrogen and progesterone receptors in salivary gland adenoid cystic carcinoma. Oral Surg Oral Med Oral Pathol Oral Radiol Endod. 1995;80:440-4.

18. Dori S, Trougouboff P, David R, Buchner A. Immunohistochemical evaluation of estrogen and progesterone receptors in adenoid cystic carcinoma of salivary gland origin. Oral Oncol. 2000;36:450-3.

19. Miller AS, Hartman GG, Chen SY, Edmonds PR, Brightman SA, Harwick RD. Estrogen receptor assay in polymorphous low-grade adenocarcinoma and adenoid cystic carcinoma of salivary gland origin. An immunohistochemical study. Oral Surg Oral Med Oral Pathol. 1994;77:36-40.

20. Nasser SM, Faquin WC, Dayal Y. Expression of androgen, estrogen, and progesterone receptors in salivary gland tumors. Frequent expression of androgen receptor in a subset of malignant salivary gland tumors. Am J Clin Pathol. 2003;119:801-6. 